\title{
Nimesulide-Hyaluronic Acid Conjugate CA102N
}

National Cancer Institute

\section{Source}

National Cancer Institute. Nimesulide-Hyaluronic Acid Conjugate CA102N. NCI

Thesaurus. Code C157231.

A covalently bound conjug ate composed of the biological polymer sodium hyaluronate (NaHA) and the hydrophobic, cyclooxygenase 2 (COX-2) inhibitor and cytotoxic agent nimesulide (Nim), with potential antineoplastic activity. Upon intravenous administration of Nim-HA conjug ate CA102N, the HA moiety targets and binds to CD44. Following endocytosis of CA102N and enzymatic degradation within the lysosomal compartment, $\mathrm{Nim}$ is released inside CD44-expressing tumor cells, causing Nim-mediated induction of cell cycle arrest tumor cell apoptosis and decreases tumor cell growth. In addition, Nim inhibits various tumor cell signaling pathways thereby further inhibiting tumor cell proliferation. CD44, a transmembrane glycoprotein and HA receptor expressed in healthy tissue, plays a key role in cellular growth, survival, differentiation and motility. Overexpressed in a variety of cancer cell types, CD44 plays a key role in tumor cell proliferation, migration and survival. Conjug ation of HA to Nim allows for increased solubility of Nim and for targeted delivery of Nim to CD44-expressing tumor cells, thereby increasing efficacy and safety of $\mathrm{Nim}$. 